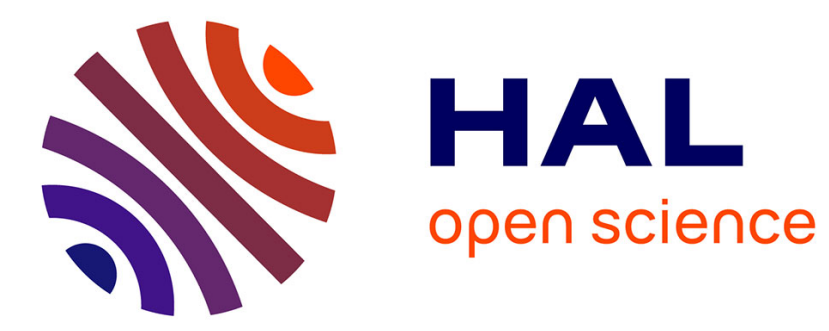

\title{
Managing uncertainty in potential supplier identification
}

Yun Ye Ye, Marija Jankovic, Gül E. Okudan Kremer, Jean-Claude Bocquet

\section{To cite this version:}

Yun Ye Ye, Marija Jankovic, Gül E. Okudan Kremer, Jean-Claude Bocquet. Managing uncertainty in potential supplier identification. AI EDAM, 2014, 28, pp.339-351. 10.1017/S0890060414000511. hal-01205179

\section{HAL Id: hal-01205179 \\ https://hal.science/hal-01205179}

Submitted on 25 Sep 2015

HAL is a multi-disciplinary open access archive for the deposit and dissemination of scientific research documents, whether they are published or not. The documents may come from teaching and research institutions in France or abroad, or from public or private research centers.
L'archive ouverte pluridisciplinaire HAL, est destinée au dépôt et à la diffusion de documents scientifiques de niveau recherche, publiés ou non, émanant des établissements d'enseignement et de recherche français ou étrangers, des laboratoires publics ou privés. 


\title{
Managing uncertainty in potential supplieridentification
}

\author{
Yun $\mathrm{YE}^{1}$, Marija JANKOVIC ${ }^{1}$, Gül E. KREMER ${ }^{2}$, Jean-Claude BOCQUET ${ }^{1}$ \\ ${ }^{1}$ Laboratoire Génie Industriel, Ecole Centrale Paris, Châtenay-Malabry, France \\ ${ }^{2}$ Engineering Design and Industrial Engineering, The Pennsylvania State University, \\ University Park, PA, USA \\ yun.ye@ecp.fr, marija.jankovic@ecp.fr, gkremer@psu.edu, \\ jean-claude.bocquet@ecp.fr
}

Corresponding author:

Dr. Marija JANKOVIC

Laboratoire Genie Industriel, Batiment Olivier, Ecole Centrale Paris, Grande Voie des Vignes, 92295 Châtenay-Malabry Cedex, France

$+33(0) 141131427$

marija.jankovic@ecp.fr

Number of manuscript pages: 28

Number of tables: 0

Number of figures:19 


\section{Managing uncertainty in potential supplier identification}

As a benefit of modularization of complex systems, Original Equipment Manufacturers (OEMs)can choose suppliers in a less constricted way when faced with new or evolving requirements. Before a supplier is selected for each module, a group of potential suppliers should be identified in order to control the uncertaintyalong with other performance measures of the new system development. In modular design,because suppliers are more involved in system development, the potential supplier identification should be combined with potential architecture identification to manage uncertainty as well as requirements satisfaction level bypotential suppliers. In this paper, we propose an Architecture \&Supplier Identification Tool (ASIT), which generates all possible architectures and corresponding suppliers based on new requirements through matrixmapping and propagation. Using ASIT, the overall uncertainty and requirements satisfaction ofgenerated architectures can be estimated. The proposed method aims at providing decision support for the early design stageand thereby helping companies to have an integrated view of suppliers and system architectures to better satisfy customer requirements and reduce risk.

Keywords: complex system design, modularity, potential supplier identification,uncertainty management 


\section{Introduction}

In order to reduce complexity and increase manageability of complex systems, one of the principles used in systems engineering is to cluster system elements into larger chunks(Chiriac et al., 2011); this is known as modularization.For diminishing or managing time-to-market and cost, the design and manufacturing of modules is often outsourced to different suppliers. The supplier companies and the OEM together form an extended enterprise (Nguyen Van, 2006).

In modular design,interfaces shared among modules in a given system architecture are usually specified and standardized(Ro et al., 2007), so that changes in one module of the system do not require changes in other parts of the system(Hoetker, 2006). This affords OEMthe ability to choose suppliers more freely vis-à-vis the evolving system requirements.

Before choosing suppliers for a new system, the OEM needs to first identify a group of potential suppliers, let them submit proposals, and then choose a suitable supplier for each module after negotiation.Normally, OEMs tend to use those suppliers with which they have a prior history of cooperation,since past interactions usually improve communication between buyer and suppliers(Levinthal and Fichman, 1991; Singh and Mitchell, 1996). This leads to faster, lower cost procurement and more successful system development (Hoetker, 2005). However, modules from prior suppliers maynot always satisfy all buyer requirements. In such situations, the OEM needs to find new suppliers of suitable new modules and technical capabilities.New suppliers and new modules add uncertainty due to various reasons (e.g., supplier's capabilities to cooperate well with the OEM, technological uncertainty ofnew modules, and the uncertaincompatibilitybetween modules).

Uncertainty can impact decision-making as attested by several studies. For example,Janssen et al. (2010) assessed the influence of presenting data with or without the uncertainty information on decision-making. A statistically significant shift in preferences 
was observed when uncertainty information was presented. Uncertainty integration was also found important in system architecture generation (Marie-Lise et al., 2012).In complex system design, suppliers are more and more tightly integrated intodesign process(Le Dain et al., 2011). Consideration of interfaces(Tripathy and Eppinger, 2011), cost reduction(Nepal et al., 2012), platform policy(Zhang et al., 2008) andnew technology integration (Chiu and Okudan, 2011)require integrating suppliers startingin early design stages. However, very few methods considereduncertaintywhile integrating assessment of supplier capabilities in system architecture generation. By proposing an Architecture \& Supplier Identification Tool (ASIT),we respond to the need forcontrolling overall system uncertainty when combining architecture generation and supplier identification.

In this paper, section 2 addresses different concepts of modularity as well as approaches that are specifically designed for supplier selection. Section 3 discusses different types of uncertainty, and argues forthe need to integrate uncertainty information in early design. An overall ASIT process is presented and discussed. In section 4, a case study on powertrain design is used to illustratethe ASIT. In order to studyifthe consideration of uncertainty changes choices made in supplier identification, we also compare ASIT with Concept Selection Method (CSM) by King and Sivaloganathan (1999). CSM is a well-known deterministic approach for concept evaluation that does not consider overall uncertainty. The difference in results along with use contextsof these two approaches is discussed in section 5. Finally, we providea discussion and our conclusions in section 6 and 7, respectively.

\section{Background}

\subsection{Modularity in complex systems}

A complex system is a system with numerous components and interconnections, interactions or interdependencies that are difficult to describe, understand, predict, manage, design, and/or 
change (Magee and de Weck, 2004). Systems and complex systems can be decomposed into different levels of modules, and the number of modules increases as the grain size of modules decreases(Chiriac et al., 2011). An example of decomposition of a vehicle system is shown in Figure 1.In this context, a module is defined as a chunk if it is tightly coupled within and loosely connected to the rest of the system (Gershenson et al., 2003). Normally, different levels of modules are also systems or complex systems themselves. Therefore, the method proposed in this paperapplies for systems and complex systems at any level of theirdecomposition. For example, the case study illustrates method application on a powertrain, which is a complex system, and alsoa first level module in Figure 1.

Figure 1 Partial decomposition of a vehicle system (adopted from Van Eikema Hommes (2008))

\subsection{Modularity in buyer - supplier relations}

According to Fixson and Park (2008), there is a substantial literature streamsuggesting that many products are becoming more modularover time; andthe modularity ofproducts leads to modularity of organizations (Garud et al., 2009). For example, in their empirical work Ro et al. (2007)found that the emergence of modularity in product designis changing the structure of the extended enterprises in American auto industry.The traditional U.S. supplier management model is as shown on the left of Figure 2. According to Ro et al. (2007), in the traditional supplier management model, the parent department (e.g., chassis department) is further divided into more specialized functional departments (e.g., suspension, steering and braking). Each of the functions is undertaken by an OEM release engineer who manages the first-tier suppliers. In this case, the OEM directly interacts with their suppliers.

The desired form of the U.S. supplier model is called "the systems integrator model"(Ro et al., 2007), which is shown on the right of Figure 2. In this form, a lead supplier manages and coordinates the design and assembly of large-scale modules and systems across a number of other suppliers.In this case, the OEM needs to communicate only with the 
integrator suppliers, i.e. OEMis concerned about the high level modules (e.g., chassis, powertrain, etc.). The integrator suppliers work more independently in this case, and the structure of the extended enterprise is more loose and flexible, implying the formation of a "modular organization".

Figure 2 Influence of modularity on supplier management model (adopted from Ro et al. (2008))

The ease of reconfiguration of organizational actors in modular organizations allows "modular innovation", by which firms improve their products by incorporating improvements in various product modulesthat may occur at different rates for different modules(Langlois and Robertson, 2002). It also allows a firm to select the best supplier for a given module at a given time (Garud and Kumaraswamy, 1995). The proposed supplier identification tool in this paper assumes that the context in which the tool is used reflects the above mentioned buyersupplier relations and that the tool is proposed as a decision support tool for the said context.

\subsection{Supplier identification and selection methods}

Petersen et al. (2005) demonstrated that "A careful and complete analysis of potential suppliers, leading to the selection of a supplier with the right capabilities and culture to work on the project was positively associated with effective decision making by the project team during the new product development process". There are hundreds of prior works concerningsupplier identification and selection. Most of the supplier selection methods are provided under the traditional product development decision making process, i.e., first the product architecture is fixed by the OEM, then production/manufacturing method is decided; based on these decisions, suppliers are selected(Nepal et al., 2012). In these methods, product architectures are fixed before supplier selection. The supplier selection is usually based upon financial and managerial criteria such as quality, cost, delivery and performance, etc. In early design, however, such data is not necessarily available and is also uncertain. Reviews of 
supplier selection criteria can be found in Ha and Krishnan (2008), Chiu and Okudan (2011) and Ye et al. (2013). The publishedsupplier selection methods under this context are oftenMulti-Criteria Decision Making (MCDM) methods using mathematical, statistical, artificial intelligent or a combination of these methods. Surveys of these methods can be found in various publications such as byde Boer et al. (2001), Ha and Krishnan (2008) and Chiu and Okudan (2011).

Because of the emergence of modularity, suppliers are more involved in the product design phase. Therefore, companies started to consider supply chain issues during product development.For example, studies were carried out for matching product development and supply chain design. Ülkü and Schmidt (2011) studied the matching between product modularity leveland the supply chain configurations, i.e. the buyer-supplier collaboration level during product design.Pero et al. (2010)studied how new product development and supply chain variables were related to each other; they found that innovativeness had a strong effect on supply chain complexity and matching product features with supply chains improved performance.Some methods are also provided to address product development and supply chain issues simultaneously. Lamothe et al. (2006) proposed a mixed integer linear programming model to helpchoose product family variants in a way that the operating cost of the supply chain delivering the product is optimized.More specifically, we have foundthree studies that consider product design and supplier selection conjointly.Zhang et al. (2008) developed a mixed integer linear programming model to support product platform design. The main objective was to balance the commonality and variety of the product platform. The suppliers were considered simultaneously with product platformto reduce cost.Chiu and Okudan (2011) proposed a graph theory based method considering product design and supply design simultaneously. In their work, product functions, assembly issues, and supply chain performance wereconsidered in early product design stage. The main objective was to 
optimize product cost and lead-time. Nepal et al. (2012) proposed a fuzzy logic based framework to tackle product design and supply chain design at the same time. Their objective was to minimize the total supply chain costs, and maximize total supply chain compatibility. Therelevant state-of-the-art in concurrent product and supply chain design is summarized by Gan and Grunow (2013).

As it can be seen above, among existing studies, Zhang et al. (2008), Chiu and Okudan (2011), and Nepal et al. (2012) addressed product architecture generation and supplier selection simultaneously. All of these consider the cost issue as their main objective. Chiu and Okudan (2011) also considered lead-time, and Nepal et al. (2012) tackled supply chain compatibility issue. However, none of the existing works considered overall uncertainty,whichisan important issue in early design. Because of the frequent high level innovation integration and uncertainty in early complex system design, we address this gap.

\section{Proposition for SupplierInformation Integration}

\subsection{Uncertainty sources in supplier identification}

De Weck et al. (2007) defined uncertainty as "an amorphous concept that is used to express both the probability that certain assumptions made during design are incorrect as well as the presence of entirely unknown facts that might have a bearing on the future state of a product or system and its success in the marketplace." Funtowicz and Ravetz (1993) stated that the uncertainty comprises information about the simplifications made during the translation of a natural system into a model.

Many previous works classified uncertainty for early product and system design (e.g., Clarkson and Eckert, 2005; McManus and Hastings, 2006; De Weck et al., 2007). The risk management in early design was also investigated by Lough et al.(2009), Van Wie et al. (2005),Altabbakh et al.(2013) and others.In the context of this work, we consider the 
underlying uncertainty of choosing new suppliers and new modules during supplier

identification.

We identified three sources of uncertainty inusing new suppliers and modules: (1)uncertainty related to suppliers' capabilities to cooperate well with the OEM, (2) the probability that a module can be successfully developed, and (3) the compatibility between the modules. For example, supplier A may be able to provide a module B which potentially satisfies the requirements well. However, in reality, the supplier A may not be able to cooperate well with the OEM, and thus the module B may not be successfully developed. Moreover, even though the module B is developed, it may not be compatible with other modules. The uncertainty of all these issues should be considered when reviewing the high satisfaction score of supplier A.

\subsection{Architecture and Supplier Identification method}

In order to integrate previously discussed system architecture uncertainties conjointly with supplier capability relateduncertainties, we propose an Architecture \& Supplier Identification Tool (ASIT). ASIT is a matrix-basedmethod containing information related to requirements, functions, modules, suppliers, and uncertainties. The main objective is to support decision making of the design team in architecture generation and supplier identification.Figure 3 presents an overview of the ASIT, which contains four phases that are automated by a MatLab program.

Figure 3Overview of the ASIT

Due to uncertainty management, complex systems are rarely designed from scratch. Therefore, project documents regarding the requirements, functions, and modules usually exist; thus, design information is captured and reused.This information capture and reuse is often facilitated through software (e.g., DOORS). However,various types of data are rarely 
stored in one place. The idea of ASIT is to store critical, high-level data (pertaining to functions but also requirements, modules, and other types of information) on previous projects within amatrix system.The matrix system is composed of aDesign Structure Matrice (DSM) and sixDomain Mapping Matrices (DMMs), as shown in Figure 4.

Figure 4The matrix system used in the ASIT

When starting a new project, usually the project manager organizes a one to three day workshopto discuss innovation integration, different system architectures, as well as other constrains.These workshops are attended by experts of different domains in order to cover overall system knowledge.With the support of the matrix system in ASIT, the expertscan choose the adequate existing requirements from the list, and if necessary add new requirements to it. Based upon the requirement-function relations stored in matrix 1 , the existing functions related to the defined requirements can be found. Fundamentally, this is a cognitive phase tackling new and existing requirements, where experts will discuss and allocate them to existing functions or create new functions. The functions, in this context, can be seen as translations of requirements to technical language, describing what the module/system should do from a technical point of view. Experts also discuss module typesthat are needed based on functions, and relations between new functions and module types.Matrices 1 and 2 can be updated after these discussions. The main difficulty inthis phase is the expression of requirements and functions due tovarious semanticpossibilities. Here, we assume that designers/engineers are able to define and use a shared language and understanding. Clearly, semantic consistency in reference to functions, etc. is needed. After the update of matrices 1 and 2, the ASIT can automatically point to (calculate) unsatisfied functions by existing systems. In phase one (using matrices 1,2 and 7), how well OEM's existing products (e.g., existing powertrains) satisfy the requirements can be estimated. Subsequently, the functions that cannot be satisfied are identified based on requirement- 
function relations in matrix 1 . In phase two, new modules that can potentially satisfy the unsatisfied functions and new suppliers are found externally, or proposed by experts, and thereby updating matrices $2,3,4,5$, and 6 . Then,ASIT can automaticallygenerateall possible architectures based on the function - module relationsprovidedin matrix 2. In phase three, uncertainty of generated architectures is calculatedbased on uncertainty of modules, compatibility between modules, and uncertainty of suppliers' capabilities. The needed information is stored in matrices 4,5 , and 6 .The requirements satisfaction by generated architectures is calculated. Finally, in phase four, using the uncertainty threshold and the requirements satisfaction threshold defined by the experts, the generated architectures are filtered by the ASIT to identify potential architectures and corresponding suppliers. As explained above, information stored in the matrix system comes from two sources: (1) information estimated by experts, and (2) information from existing products.For expert estimation, a group of experts work together to provide estimation by using predefined levels (as shown in Figure 5 and 6). The information on existing products is considered already stored in the matrix system;because after each project, the related data in the matrix system is updated based on project outcomes. Experts need to provide four types of information during the process of the ASIT. The first type is of percentages used in matrix 1, representing the level a function fulfills a requirement. The second type is about satisfaction levels used in matrix 2, representing how well a module satisfies a function. The third type is probabilities as defined inFigure 6,describinguncertainties in matrices 4,5 , and 6 . The last type of information is binary, and is used to define whether one element belongs to another element (matrices 3 and 7).

The satisfaction levels used in the ASIT are defined as "interval scales" (Stevens, 1946), so that operations such as addition, subtraction, multiplication by a real number are meaningful. Ten levels (1-10) are used for representing satisfaction, "1" is defined as "very 
inadequate solution", and " 10 " is defined as "ideal solution". The unit of measurement is $1 / 10$ of the satisfaction difference between " 1 " and " 10 ". The descriptive meanings for the satisfaction levels are adapted from Fiod-Neto and Back's parameter value scores (Fiod-Neto and Back, 1994, pp. 35-45), and are shown in Figure 5. " 0 " is used to represent "the module does not provide the function". During workshops, experts use the linguistic terms in Figure 5 to provide their estimations, then the linguistic terms are quantified using 1-10 scale equivalents.

Figure 5 Linguistic terms for satisfaction levels (adopted from (Fiod-Neto and Back, 1994))

Experts always use linguistic terms to provide their estimation of probabilities(Meyer and Booker, 2001). Many previous works provided natural language terms associated with probabilities (e.g., Boehm, 1989, p. 133;Conrow, 2003, pp. 491-513; Hamm,1991;Lichtenstein and Robert, 1967; and Moore, 1983). However, in these previous works, the proposed probability-related terms were different (Hillson, 2005). Therefore, based on linguistic terms listed in works of Hillson(2005) and Halliwell and Shen (2009), we propose a list of linguistic terms as shown in Figure 6. The experts provide their estimations using these linguistic terms.

Figure 6 Linguistic terms for probabilities

ASIT leverages the use of matrices as a database form in early design for modular complex systems; this has two main advantages.First is that because only the first tier suppliers are considered, the number of module is limited, and thus the usage of matrices is practical. The explicit form of matrices makes the relations between elements clear, facilitating comprehension and communicationbetween experts. In addition, the storage of two dimension matrices does not require specific techniques. This flexibility enables companies to continue using tools that they are familiar with. Standardization in terms of the vocabulary used while describing requirements, functions, etc. will ensure consistency; and it 
is assumed that company-centric standard vocabulary will be used while filling the ASIT

\section{matrices}

The main mapping flow in ASIT is requirement - function - module supplierrelations as shown in matrices 1,2 and 3. There are prior works that also use matrix systems, such as the Quality Function Deployment (QFD), the concept selection method (King and Sivaloganathan, 1999), the architecture generation method (Bryant et al., 2005), and the multiple-domain design scorecard method(Jankovic et al., 2012).In QFD, the customer requirements - design requirements - parts design - manufacturing process - build quantity relations areused to transform customer desires into design characteristics for each stage of the product development (Rosenthal, 1992).In the methods developed by King and Sivaloganathan (1999) and Bryant et al.(2005), the function - componentrelations are used to generate all possible concepts.InJankovic et al. (2012)'s method, the function - structure performance relations are used to generate the six design assessment cards.Across all of these matrix-based methods, ASIT is the first one to incorporate supplier information and uncertainty.Our approach in potential supplier identification also features a "variable" view of the design (i.e., design is not fixed). In addition, uncertainties related to various systemsupplier aspects are considered.

\section{Implementation}

\subsection{Case Study Description}

In this paper, we focus on the powertrain design for a motor vehicle. Due to innovation integration as well as fuzziness in early design(Marie-Lise et al., 2012; De Weck et al., 2007), a vehicle is usually decomposed into two or three levels of subsystemsat this stage. The powertrain is one of the high-level subsystems that can be further decomposed. The main objective in designing a powertrain is to provide adequate propulsion with minimal use of fuel 
while emitting minimal hazardous by-products or pollutants.For the sake of simplicity, only gas engine and hybrid engine architecturesare considered in this case study.

A powertrain is a system of mechanical parts in a vehicle that first provides energy, then converts it in order to propel the vehicle. In a traditional gas-engine vehicle, the engineprovides power converting from other sources of energy. The transmission then takes the power, or output, of the engine and, through specific gear ratios, slows it and transmits it as torque. Through the driveshaft, the engine's torque is transmitted to the final drive (wheels, continuous track, etc.) of the car. In hybrid electric vehicles, besides the four modules mentioned above, batteries provideelectricalenergy, and electric motors are used to transform electric energy into torque. Therefore in this study, we consider six types of modules including engine, battery, transmission, electric motor, driveshaft and final drive. A powertrain system of a modern automobile is shown in Figure 7.

Figure 7Powertrain system of a modern automobile(Akehurst, 2007)

In general, when considering couplings that exist within apowertrain system as well as new architectures that are emerging due to new technologies (e.g., hybrid and electric vehicle), the powertrain can be considered as a complex system.Michelena and Papalambros (1995) also stated that "in practice, this task is completed incrementally by trial and error and is costly and time consuming." Further, as a system of variables to be optimized it is overwhelming; Wagner (1993)showed through tested mathematic models that a powertrain system design can have 87 design relations, 127 variables, and 57 degrees of freedom.However, inthis case study, not all subsystems and technologies are considered in

\section{order to simplify the explanations.}

Due to the increasing demand of lower emissions and higher fuel efficiency, the OEM plans to design a new powertrain for their motor vehicle to better satisfy market needs. In this case study,the new powertrain needs to satisfy 6requirements (requirements (1) to (5) are 
adapted fromMichelena and Papalambros (1995)), including: (1) fleet averaged corporate average fuel economy (CAFE) standard (Violation of this standard results in proportional fines.), (2) acceleration time (This directly relates to customer perceived performance.), (3) Cruising velocity at grade (Relates to the speed at which vehicle can climb a $6 \%$ grade in forth gear.), (4) The 0-60 $\mathrm{mph}$ time (This requirement relates to average speed vehicle acceleration over the speed range of the engine.), (5) Greenhouse gas emissions (This measure shows a vehicle's impact on climate change in terms of the amount of greenhouse gases (e.g., CO2) it emits.), and (6) Rechargeable by external electric power (This requirement indicates that the OEM would like to develop a plug-in hybrid electric vehicle using rechargeable batteries, the new trend in the market). These requirements can be satisfied by certain functions (e.g., transform energy to torque), andeach of the functions is satisfied by one or more modules(Ulrich and Eppinger, 2000).For the new powertrain development, the OEM expects the optimum performance of the system, but at the same time, the uncertainty of the system development has to be controlled.

\subsection{Phase I}

For the new powertrain design, a list of requirements is defined by a group of experts. The aim of this phase is to use ASIT to calculate how OEM's existing powertrains satisfy these requirements, and which functions are not satisfied, pointing to the need for new module development.

Existing information is stored in the ASIT matrix system. When starting a new project, the matrices $M_{1}$ and $M_{2}$ need to be updated by experts with new requirements and functions. Identification of requirementsrequires experts first to choose appropriate existing requirements, and then add new requirements to the list, if necessary. By using the requirement - function relations in matrix $\mathrm{M}_{1}$, functions that satisfy these requirements are 
allocated. Experts allocate newly identified requirements to existing functions or add new functions. With new requirements and functions added, the requirement - function relations in matrix $\mathrm{M}_{1}$, and function satisfaction by modules in matrix $\mathrm{M}_{2}$ are estimated by experts. The updated matrix $\mathrm{M}_{1}$ is shown in Figure 8 , where the requirement "rechargeable by external electric power" is a new requirement, and the function "accept recharge" is a new function.

Figure 8 Requirement - function relations

The updated matrix $\mathrm{M}_{2}$ is shown in Figure 9, where a new function is added, and module types needed are also identified by experts.

Figure 9 Function satisfaction level by modules

After $\mathrm{M}_{1}$ and $\mathrm{M}_{2}$ are updated, ASIT leverages information from $\mathrm{M}_{1}, \mathrm{M}_{2}$ and $\mathrm{M}_{7}$ (see Figure 10) to estimate requirements satisfaction by existing systems. The $M_{7}$ is an excerpt ofOEM's existing powertrains.In this case study, the OEM successfully developed two types of powertrains in the past (i.e., regular gas engine powertrain and hybrid, as shown in matrix $\mathrm{M}_{7}$ inFigure 10), which are used as foundationsfor the new product development. In the matrix $\mathrm{M}_{7}$,"1" represents "the module belongs to the architecture", and " 0 " represents "the module does not belong to the architecture".

Figure 10Composition of existing powertrains

In order to propagate the function satisfaction by modules (Figure 9) to the function satisfaction by architectures, the composition of the existing powertrains (matrix $\mathrm{M}_{7}$, Figure 10) is considered. How a system satisfies a function depends on the capability of its relevant modules. When there is only one module in the product that is designed to satisfya function, the satisfaction level of the function by the product is consideredthe same as the satisfaction level of the function by the module. When there are multiple modules satisfying the function, 
the satisfaction level is defined as the average of satisfaction levels of the modules. For example, the gas powertrain has only one module (the engine 1) fulfilling the function "provide power". Therefore, if the "engine 1" satisfies the "provide power" function at level 8 , the gas powertrain should also satisfy this function at level 8 , as shown in matrix $\mathbf{M}_{\text {fun-arch }}$ in Figure 11.The satisfaction levels here represent "how good a module is with specific regards to a function" qualitatively. The average of satisfaction levels is a simplification adopted in this work; the weights of modules for satisfying a function can also be considered.

Figure 11 Function satisfaction level by existing products

In order topropagate the satisfaction of functions to the satisfaction of requirements, the requirement - function relations $\left(\mathrm{M}_{1}\right.$, Figure 8) are used. Numbers in this matrix represent the percentage that a function satisfies a requirement. The sum of each row of the matrix can be greater or equal to 0 and smaller or equal to 1 , since the requirements may be only partly satisfied.For propagating the satisfaction of functions to the satisfaction of requirements, we use the formula:

$$
M_{r e q-a r c h}=M_{1} \times M_{\text {fun-arch }}
$$

The requirements satisfaction of the existing powertrains is shown in Figure 12.

Figure 12 Requirement satisfaction of existing products

We define that the level 5 represents the "satisfactory solution", and we further define that a requirement is unsatisfied if its satisfaction level is lower than 5 by at least one architecture. Therefore, the requirements "0-60 mph time", "low greenhouse gas emission", and "rechargeable by external electric power" are unsatisfied.Using $\mathrm{M}_{1}$ inFigure 8 , one can see that the requirement " $0-60 \mathrm{mph}$ time" is related to the function "provide power"; the requirement "low greenhouse gas emission" is related to the function "respect environment"; and the requirement "rechargeable by external electric power" is related to the function 
"accept recharge". Then, by using $\mathrm{M}_{2}$ in Figure 9, one can see that the satisfaction of these three functions depends on the engine and the battery. Therefore, new engines and batteries, which can potentially satisfy these functionsneed to be identified.

\subsection{Phase II}

The objective of this phase is to find/propose potential new solutions for unsatisfied functions by experts, and then use ASIT to generate all possible architectures.After searching fornew modules provided either by new or existing suppliers, two new engines and two new batteries are found.Both of the two engines are from new suppliers; one of the new batteries is from a new supplier, while the other one is from an existing supplier of the OEM. Now the matrix system needs to be updated with new modules and new suppliers. Function satisfaction levels of the new modules in matrix 2 , compatibility between modules in matrix 4 , uncertainty of modules and suppliers in matrices 5 and 6 are provided by a group of experts, and recorded in

\section{the matrix system.}

The updated function satisfaction levels of modules are as shown in $\mathrm{M}_{2}^{\prime}$ inFigure 13. It can be seen that the two new engines perform well for functions "respect environment" and "economize fuel", but not as much for "provide power" in comparisonto existing modules. The two new batteries perform well in satisfying "provide power" and "accept recharge" but for other functions they do not show much advantage. Based on modules shown in $\mathrm{M}_{2}^{\prime}$ in Figure 13, all possible architectures are generated.

Figure 13Function - module relations with new modules

As indicated by experts during phase 1 when identifying module types, the powertrain of a plug-in hybrid electric vehicle needs an engine, a battery, a transmission, an electric motor, a driveshaft and a final drive. Therefore, by taking one module from each type of modules mentioned in $\mathrm{M}_{2}^{\prime}$, all possible architectures are generated (see Figure 14). 


\subsection{Phase III}

The objective of this phase is to use ASIT to calculate uncertainty and requirements satisfaction for all possible architectures. The generated possible architectures are of different satisfaction levels and uncertainty.The uncertainty of each module (represented in matrix $\mathrm{M}_{5}$ in Figure 15), the compatibility between modules $\left(\mathrm{M}_{4}\right.$ in Figure 15$)$, and the uncertainty of suppliers' capabilities $\left(\mathrm{M}_{6}\right.$ in Figure 15$)$ need to be considered for calculating the uncertainty.

The matrix $\mathrm{M}_{4}$ shows interface compatibilities between modules due to innovation integration. We define that "not compatible" is equal to "0", "perfectly compatible" is equal to "1", and a number between "0" and " 1 " represents the probability that the two modules work well together. Compatibility betweenmodules in existing productsisdefined as "1", whileother compatibilities are between 0 and $1 . \mathrm{M}_{4}$ is symmetrical, and the elements describing the relations between modules, which satisfy the same function, do not need any interpretation.The matrix $\mathrm{M}_{5}$ represents the uncertainty of modules. Similar to the definition of compatibility, we define "not mature at all" as " 0 " and "mature" as " 1 ", a number between " 0 " and " 1 " represents the probability that the module can be developed successfully by the company. Similarly, the matrix $\mathrm{M}_{6}$ represents the probability that a supplier and the OEM can work well together.The matrix $\mathrm{M}_{3}$ represents the relations between modules and suppliers, where the number " 1 " represents that the supplier provides the module.

Since module uncertainty, supplier uncertainty and compatibility between modules can all be consideredinprobabilistic terms, we define the uncertainty of an architecture as the product of all its modules' uncertainties, its suppliers' uncertainties and the compatibilities between the modules. This definition anchors on the independence of probabilities. The matrices $\mathrm{M}_{3}, \mathrm{M}_{4}, \mathrm{M}_{5}$ and $\mathrm{M}_{6}$ are shown in Figure 15 . 
Done in a similar way as in calculating the requirements satisfaction by existing products, the requirements satisfaction by possible architectures is calculated usingthematrix $\mathrm{M}_{2}^{\prime}$ (in Figure 13) and the matrix $\mathrm{M}_{1}$ (inFigure 8). In this case, we assume equal importance of the requirements (this assumption can be changed if needed), anoverall requirements satisfaction score is obtained for each of the possiblearchitectures by calculating the average of all requirements satisfaction scores for the architecture, as shown by the equation below:

The overall requirements satisfaction by architecture $X=\frac{1}{6} \sum_{Y=1 \ldots 6}$ Satisfaction of requirment $\mathrm{Y}$ by $\mathrm{X}$ The obtained uncertaintiesand satisfaction levelsare presented in Figure 16.Considering the lack of precision in expert estimation, only two decimal numbersare kept for the results.The "uncertainty" represents the overall uncertainty level of an architecture. Bigger the number is, greater the level of confidence we have for the architecture. The uncertainty result obtained here cannot be translated directly to the possibility of success of an certain architecture. The "satisfaction" represents the satisfaction level of the requirements by an architecture. Bigger the number is, better the architecture satisfies the requirements.

Figure 16 Uncertainty and requirements satisfaction estimation for possible architectures

\subsection{Phase IV}

The aim of this phase is to use ASIT to filter possible architectures by their uncertainties and the requirement satisfaction levels. The thresholds are provided by experts.

The OEM tends to keep the architectures with the best performances whilerejecting highly uncertain architectures in view of theuncertaintyrelated to the project. For this project, the uncertainty threshold is set to 0.02 , and the satisfaction threshold is set to 5 . Thus,all architectures with uncertainty lower than 0.02and satisfaction level lower than 5 are rejected. 
After filtering, 3out of the 12 generated architectures remain(architectures 6, 7, 8), as shown in Figure 17, for final consideration.

Figure 17Uncertainty and satisfaction filtering of possible architectures

The composition of the architectures 6,7, and 8 can be found in Figure 14, and the suppliers for the modules are recorded in matrix $\mathrm{M}_{3}$ in Figure 15. Since the modules "engine 1", "battery 1" and "battery 3"do not belong to any of the three selected architectures, these three modules are deleted from the initial list. With regard to suppliers, only suppliers that are contributing to selected modules are kept for further consideration. That is why the supplier 5 is not considered further.

Finally, for battery, transmission, electric motor, driveshaft and final drive, only one supplier remains; for the engine, three potential suppliers are identified for further negotiation.

\section{Comparison}

There are several possibilities for comparing the ASIT method to others, includingthe method proposed Bryant et al.(2005), change propagation methodproposed by Clarkson et al.(2004), and risk management in early designproposed by Lough et al.(2009). However, in order to investigate how consideration of uncertainty changes supplier identification, we need to compare the ASIT to a similar matrix-based method that does not consider uncertainty. The Concept Selection Method (CSM) proposed by King and Sivaloganathan (1999) is a wellknown matrix based approach allowing ranking different conceptswith consideration of function satisfaction. The consideration of function satisfaction is rare in many complex system generation approaches, and that is why CSM was chosen for the comparison. The CSMuses two matrices to represent function satisfaction by modules and compatibility between modules, respectively.For eacharchitecture, the summation of function satisfaction and the product of the compatibility score are multiplied, providing an overall 
score for each architecture. ASIT and CSM do not entirely consider the same information;the inputs and outputs of these two methods are represented in Figure 18. The CSM and the ASIT use different scales for inputs. The CSM requires that "the total score for all modules with respect to each function to equal 1.0", and the compatibility between two modules is represented using a $0-2$ scale. In order to allow the comparison, the inputs of the two methods are normalized.

Figure 18 Main differences between the CSM and the ASIT

In CSM, overall scoresfor each architecture are calculated and ranked(see figure 19). In ASIT, only the architectures with requirements satisfaction and uncertainty above the thresholds are identified, with a set of suppliers contributing to a given architecture design (Figure 19).

Figure 19 Comparison of results between CSM and ASIT

One can see on the left side of the table that when compatibility is considered as part of the performance, the architecture 2 receives a very high score.This is because this architecture is an existing architecture, and thus the "compatibility performance" is very high.Therefore, when adding the "function satisfaction performance" and the "compatibility performance" together, this architecture receives a good performance score although the "function satisfaction performance"alone is not good enough.We can also see thaton the left side of the table, the architecture 12 is ranked as the third best architecture. However,it isnot among the remainingarchitectureswhen considering overall uncertainty, since its uncertainty is lower than the set uncertainty threshold (0.02). Further analysis reveals that the module "battery 3 " in the architecture 12 is of an uncertainty value 0.2 , which means that although this module can potentially provide very good performance, its development is estimated to be very uncertain, and the probability that its supplier works well with the OEM is low (0.3). The same situation can be found for other architectures such as architectures 10 and11.Uncertainty 
consideration implies thatcertain potential architectures $(5,9,10,11,12)$ are eliminated, resulting in the elimination of supplier 5providing battery 3 used in architectures 9,10,11,12. As explained before, the battery 3 provides very good performance; however, its uncertainty is very low.

\section{Discussion}

We have seen that the consideration of overall uncertainty influences the result of potential supplier identification. This is because the suppliers, which have potentially high performance but also high uncertainty, are excluded based on the risk that the OEM is willing to take on for the project. In financial terms, return is always accompanied by risk. High return options usually also have high risk. That is why the return/risk trade-offs are necessary when making financial decisions.Using the corollary in engineering design, the concepts with better performances might also have higher uncertainty. Therefore, we propose to consider both performance and uncertainty when making decisions in architecture generation and potential supplier identification.

However, there are several limitations in this work. Firstly, as an initial step towards introducing uncertainty to supplier identification combined with architecture generation, the sources of uncertainty considered in this work may not be exhaustive. Although the information used is mostly from expert estimation, we have not considered the subjectivity in expert estimation. The sensitivity of ASIT regarding this type of uncertainty should be investigated in future works to verify the robustness of this tool. Secondly, with specific regards to performance, only requirements satisfaction is considered in this paper. Many other types of performance are also important in the supplier identification, however (e.g., sustainability,product cost and lead-time,etc). We believe that the feasibility of getting these types of information in early complex system design stage needs to be considered. Thirdly, 
the weights of requirements, and the importance of modules for satisfying a function (when the function is satisfied by more than one module) are considered to be equal in this paper. It might be fruitful to explore using varying weights. Moreover, several studies pointed out the need for investigating the impact of preference aggregation andcollaborative expert estimation. We believe that this is an important issue and it should be tested within an industrial setting. The work of Clemen and Winkler (1999) and Keeney (2009) set a good basis for future research in this aspect.Regarding the validation of the proposed tool, it will be necessary to test the tool in an industrial environment in the future.

\section{Conclusions}

Potential supplier identification is the phase of preparing supplier candidates for supplier selection by the OEMs. Because of the use of modular design in complex systems, the suppliers are more and more involved in system design, which makes the technical ability of suppliers more important to better satisfy system requirements. However, using novel architectures and suppliers with potential better performance often causes higher uncertainty.

In this paper, we proposed an Architecture \& Supplier Identification Tool (ASIT), which uses both requirement satisfaction and uncertainty threshold to filter possible architectures and suppliers. The uncertainty related to suppliers' capabilities to cooperate well with the OEM, the technological uncertainty in new modules, and the uncertainty of compatibility between modules are considered.To the best of our knowledge, the ASIT is the first supplier identification tool that combines architecture generation, and controls the overall uncertainty during this decision-making.By comparing toa method, which does not consideruncertainty using a case study of powertrain design,it is shown that considering uncertainty impacts the result of the supplier identification, and the uncertainty should be considered independently from the performance. 
Suppliers with potentially high performance may alsohave high uncertainty. The utilization of the ASIT in supplier identification has potential in balancing the return and the risk for the OEM, optimizingidentified suppliers. 


\section{References}

Akehurst, S., 2007. Lean Powertrain Development [WWW Document]. URL http://staff.bath.ac.uk/enssa/LPDev.htm (accessed 9.16.13).

Altabbakh, H., Murray, S., Grantham, K., Damle, S., 2013. Variations in Risk Management Models: A Comparative Study of the Space Shuttle Challenger Disaster. Engineering Management Journal.

Boehm, B., 1989. Software risk management, in: Ghezzi, C., McDermid, J.A. (Eds.), ESEC '89, Lecture Notes in Computer Science. Springer Berlin Heidelberg, pp. 1-19.

Bryant, C.R., McAdams, D.A., Stone, R.B., Kurtoglu, T., Campbell, M.I., 2005. A Computational Technique for Concept Generation, in: ASME 2005 International Design Engineering Technical Conferences \& Computers and Information in Engineering Conference. ASME, Long Beach, California, USA, pp. 267-276.

Chiriac, N., Hölttä-Otto, K., Lysy, D., Suk Suh, E., 2011. Level of Modularity and Different Levels of System Granularity. J. Mech. Des. 133, 101007-101007.

Chiu, M.-C., Okudan, G., 2011. An Integrative Methodology for Product and Supply Chain Design Decisions at the Product Design Stage. J. Mech. Des. 133.

Clarkson, J., Eckert, C., 2005. Design Process Improvement: A Review of Current Practice. Springer.

Clarkson, P.J., Simons, C., Eckert, C., 2004. Predicting Change Propagation in Complex Design. J. Mech. Des. 126, 788-797.

Clemen, R.T., Winkler, R.L., 1999. Combining Probability Distributions From Experts in. Risk Anal 19, 187-203.

Conrow, E.H., 2003. Effective risk management: Some keys to success. American Institute of Aeronautics and Astronautics, Reston VA, USA.

De Boer, L., Labro, E., Morlacchi, P., 2001. A review of methods supporting supplier selection. European Journal of Purchasing \& Supply Management 7, 75-89.

De Weck, O., Eckert, C., Clarkson, J., 2007. A Classification of Uncertainty for Early Product and System Design, in: International Conference on Engineering Design. Presented at the ICED'07, Paris, France.

Fiod-Neto, M., Back, N., 1994. Assessment of product conception: A critical review, in: Proceedings of the 1994 Lancaster International Workshop on Engineering Design.

Fixson, S.K., Park, J.-K., 2008. The power of integrality: Linkages between product architecture, innovation, and industry structure. Research Policy 37, 1296-1316.

Funtowicz, S.O., Ravetz, J.R., 1993. Science for the post-normal age. Futures 25, 739-755.

Gan, T.-S., Grunow, M., 2013. Concurrent Product - Supply Chain Design: A Conceptual Framework \& Literature Review. Procedia CIRP 7, 91-96.

Garud, R., Kumaraswamy, A., 1995. Technological and organizational designs for realizing economies of substitution. Strategic Management Journal 16, 93-109.

Garud, R., Kumaraswamy, A., Langlois, R., 2009. Managing in the Modular Age: Architectures, Networks, and Organizations. John Wiley \& Sons.

Gershenson, J.K., Prasad, G.J., Zhang, Y., 2003. Product modularity: Definitions and benefits. Journal of Engineering Design 14, 295-313.

Ha, S.H., Krishnan, R., 2008. A hybrid approach to supplier selection for the maintenance of a competitive supply chain. Expert Systems with Applications 34, 1303-1311.

Halliwell, J., Shen, Q., 2009. Linguistic probabilities: theory and application. Soft Comput 13, 169-183.

Hamm, R.M., 1991. Selection of verbal probabilities: A solution for some problems of verbal probability expression. Organizational Behavior and Human Decision Processes 48, $193-223$. 
Hillson, D., 2005. Describing probability: The limitations of natural language, in: EMEA Proceedings. Presented at the PMI Global Congress 2005, Edinburgh, UK.

Hoetker, G., 2005. How much you know versus how well I know you: selecting a supplier for a technically innovative component. Strategic Management Journal 26, 75-96.

Hoetker, G., 2006. Do modular products lead to modular organizations? Strategic Management Journal 27, 501-518.

Jankovic, M., Holley, V., Yannou, B., 2012. Multiple-domain design scorecards: a method for architecture generation and evaluation through interface characterisation. Journal of Engineering Design 23, 746-766.

Janssen, J.A.E.B., Krol, M.S., Schielen, R.M.J., Hoekstra, A.Y., 2010. The effect of modelling expert knowledge and uncertainty on multicriteria decision making: a river management case study. Environmental Science \& Policy 13, 229-238.

Keeney, R.L., 2009. The foundations of collaborative group decisions. International Journal of Collaborative Engineering 1, 4-18.

King, A.M., Sivaloganathan, S., 1999. Development of a Methodology for Concept Selection in Flexible Design Strategies. Journal of Engineering Design 10, 329-349.

Lamothe, J., Hadj-Hamou, K., Aldanondo, M., 2006. An optimization model for selecting a product family and designing its supply chain. European Journal of Operational Research 169, 1030-1047.

Langlois, R.N., Robertson, P.L., 2002. Firms, Markets and Economic Change: A dynamic Theory of Business Institutions. Routledge.

Le Dain, M.-A., Calvi, R., Cheriti, S., 2011. Measuring supplier performance in collaborative design: proposition of a framework. R\&D Management 41, 61-79.

Levinthal, D.A., Fichman, M., 1991. History Dependence in Professional Relationships : Ties That Bind.

Lichtenstein, S., Robert, J., 1967. Empirical scaling of common verbal phrases associated with numerical probabilities. Psychonomic Science 9, 563-564.

Lough, K.G., Stone, R., Tumer, I.Y., 2009. The risk in early design method. Journal of Engineering Design 20, 155-173.

Magee, C.L., de Weck, O.L., 2004. Complex system classification. Presented at the Fourteenth annual international symposium of the international council on systems engineering (INCOSE).

Marie-Lise, M., Marc, B., Marija, J., Jean-Claude, B.J., 2012. Product architecture generation and exploration using bayesian networks. Proceedings of the 12th International Design Conference DESIGN 2012 1761-1770.

McManus, H., Hastings, D., 2006. A framework for understanding uncertainty and its mitigation and exploitation in complex systems. IEEE Engineering Management Review 34, 81-81.

Meyer, M.A., Booker, J.M., 2001. Eliciting and Analyzing Expert Judgment: A Practical Guide. SIAM.

Michelena, N., Papalambros, P., 1995. A Hypergraph Framework to Optimal Model-Based Partitioning of Design Problems (Technical Report No. M-MEAM 95-02). partment of Mechanical Engineering and Applied Mechanics, University of Michigan, Ann Arbor, Michigan.

Moore, P.G., 1983. The business of risk. Cambridge University Press, Cambridge UK.

Nepal, B., Monplaisir, L., Famuyiwa, O., 2012. Matching product architecture with supply chain design. Eur. J. Oper. Res. 216, 312-325.

Nguyen Van, T., 2006. System engineering for collaborative data management systems: Application to design/simulation loops. Ecole Centrale Paris, Paris, France. 
Pero, M., Abdelkafi, N., Sianesi, A., Blecker, T., 2010. A framework for the alignment of new product development and supply chains. Supply Chain Management: An International Journal 15, 115-128.

Petersen, K.J., Handfield, R.B., Ragatz, G.L., 2005. Supplier integration into new product development: coordinating product, process and supply chain design. Journal of Operations Management 23, 371-388.

Ro, Y.K., Liker, J.K., Fixson, S.K., 2007. Modularity as a Strategy for Supply Chain Coordination: The Case of U.S. Auto. IEEE Transactions on Engineering Management 54, 172-189.

Ro, Y.K., Liker, J.K., Fixson, S.K., 2008. Evolving Models of Supplier Involvement in Design: The Deterioration of the Japanese Model in U.S. Auto. IEEE Transactions on Engineering Management 55, 359-377.

Rosenthal, S.R., 1992. Effective Product Design and Development: How to Cut Lead Time and Increase Customer Satisfaction. Business One Irwin.

Singh, K., Mitchell, W., 1996. Precarious collaboration: Business survival after partners shut down or form new partnerships. Strategic Management Journal 17, 99-115.

Stevens, S.S., 1946. On the Theory of Scales of Measurement. Science 103, 677-680.

Tripathy, A., Eppinger, S.D., 2011. Organizing Global Product Development for Complex Engineered Systems. Engineering Management, IEEE Transactions 58, 510-529.

Ülkü, S., Schmidt, G.M., 2011. Matching Product Architecture and Supply Chain Configuration. Production and Operations Management 20, 16-31.

Ulrich, K.T., Eppinger, S.D., 2000. Product design and development. Irwin/McGraw-Hill.

Van Eikema Hommes, Q., 2008. Comparsion and application of metrics that define the components modularity in complex products, in: Proceedings of ASME 2008 International Design Engineering Technical Conferences IDETC. Presented at the DTM, Brooklyn, NY.

Van Wie, M., Grantham, K., Stone, R., Barrientos, F., Tumer, I., 2005. An analysis of risk and function information in early stage design. Presented at the Proceedings of the ASME International Design Engineering Technical Conferences and Computers and Information in Engineering Conference, Amer Soc Mechanical Engineers, New York, pp. 483-496.

Wagner, T.C., 1993. A general decomposition methodology for optimal system design. University of Michigan.

Ye, Y., Jankovic, M., Bocquet, J.-C., 2013. Main Factor Identification for Early Negotiation in Product Design, in: Proceedings of the19th International Conference on Engineering Design (ICED13). Seoul, Korea.

Zhang, X., Huang, G.Q., Rungtusanatham, M.J., 2008. Simultaneous configuration of platform products and manufacturing supply chains. International Journal of Production Research 46, 6137-6162. 


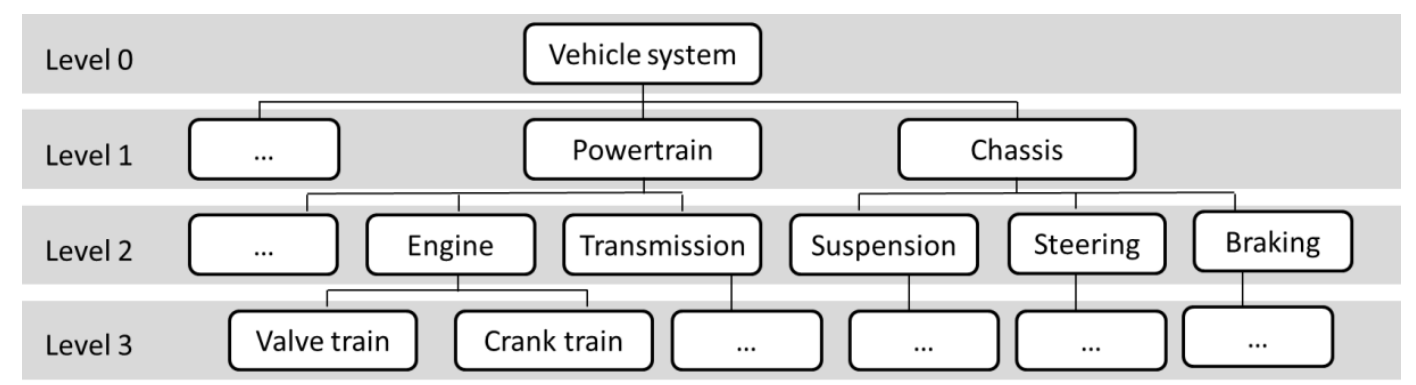

Figure 1 Partial decomposition of a vehicle system (adopted from Van Eikema Hommes (2008))
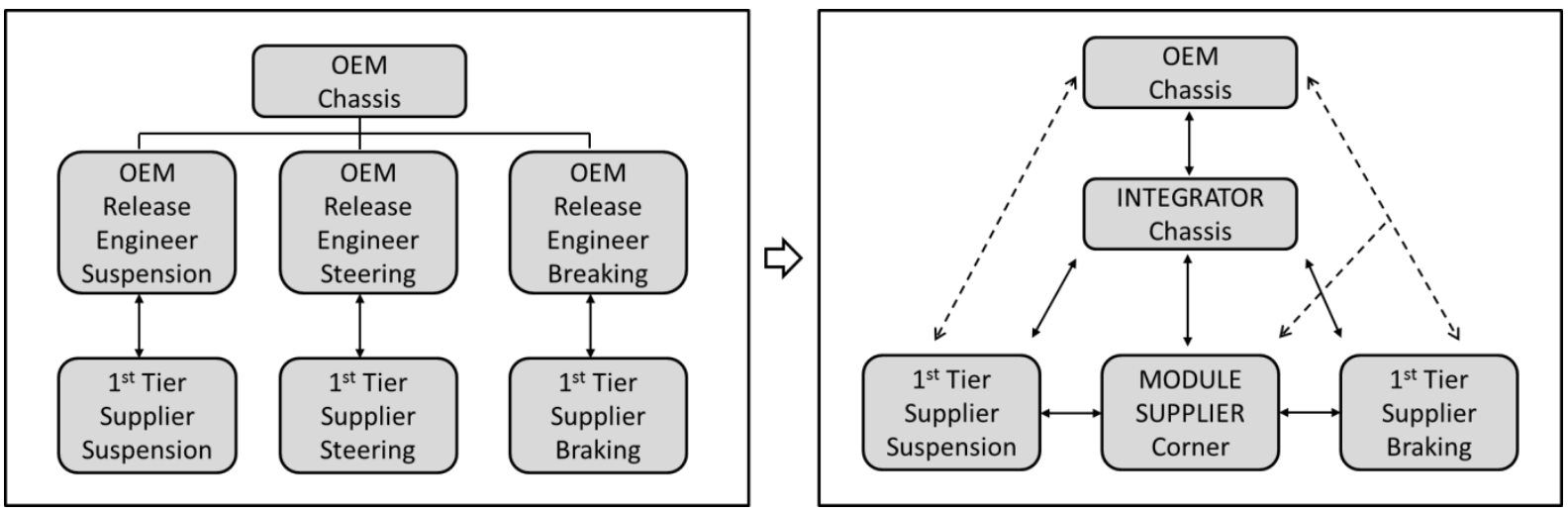

Figure 2 Influence of modularity on supplier management model (adopted from Ro et al. (2008))

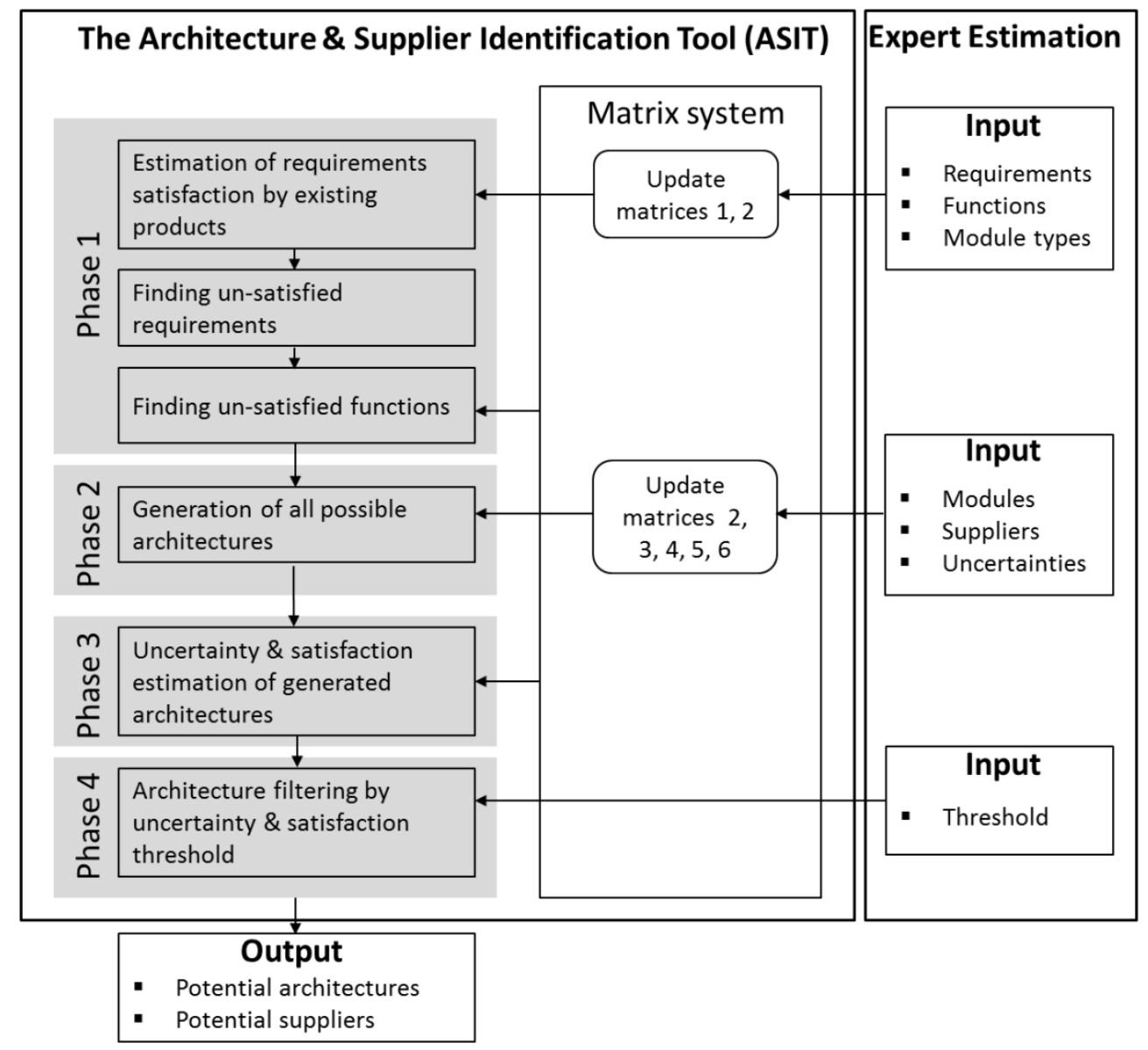

Figure 3Overview of the ASIT 


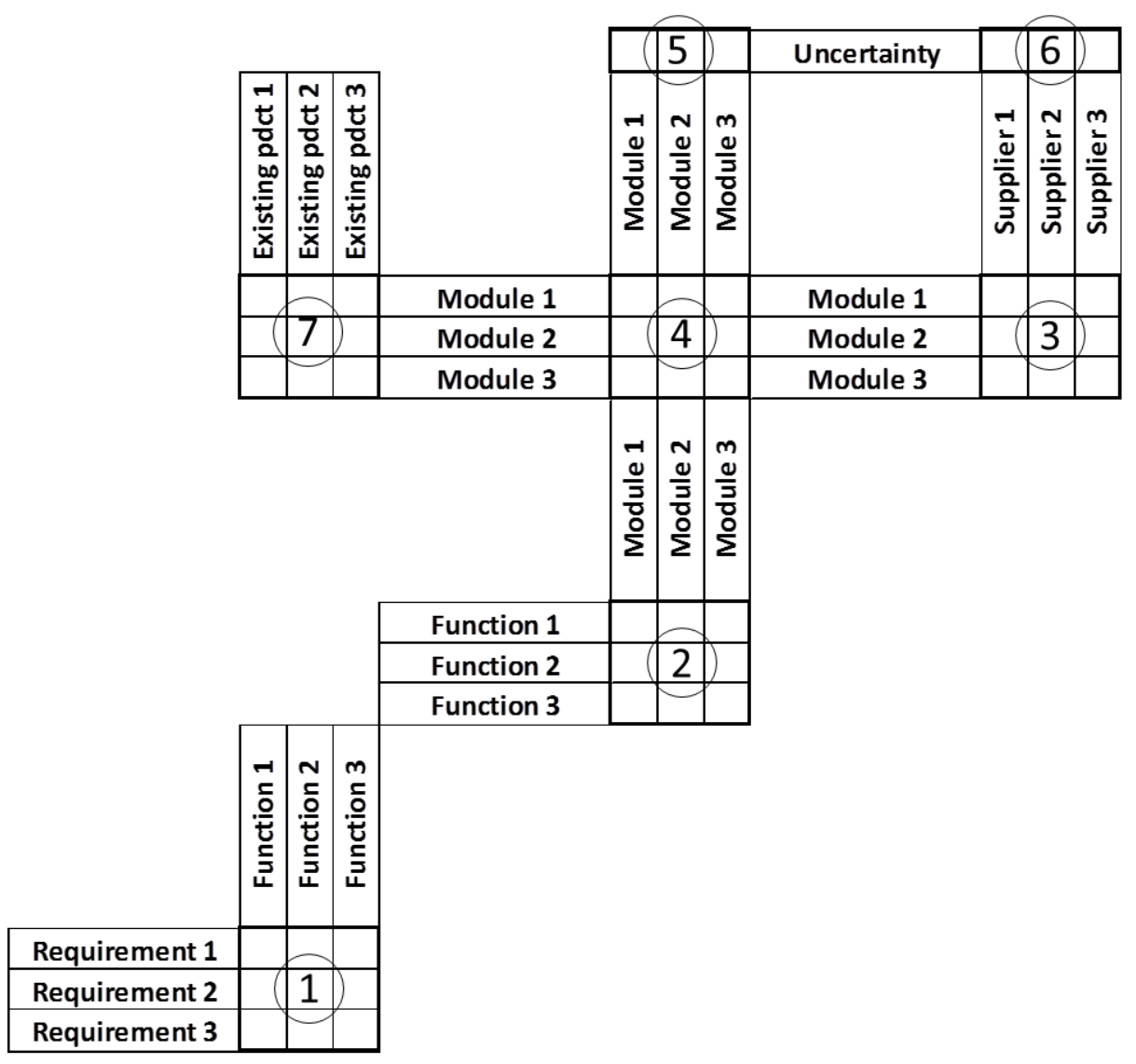

Figure 4The matrix system used in the ASIT

\begin{tabular}{lc}
\hline \multicolumn{1}{c}{ Linguistic terms } & Satisfaction level \\
\hline Very inadequate solution & 1 \\
Weak solution & 2 \\
Tolerable solution & 3 \\
Adequate solution & 4 \\
Satisfactory solution & 5 \\
Good solution with few drawbacks & 6 \\
Good solution & 7 \\
Very good solution & 8 \\
Solution better than requirements & 9 \\
Ideal solution & 10 \\
\hline
\end{tabular}

Figure 5 Linguistic terms for satisfaction levels (adopted from (Fiod-Neto and Back, 1994)) 


\begin{tabular}{lc}
\hline \multicolumn{1}{c}{ Linguistic terms } & Probability \\
\hline Impossible & 0 \\
Nearly impossible & 0.1 \\
Very unlikely & 0.2 \\
Quite unlikely & 0.3 \\
Possible & 0.4 \\
Even chance & 0.5 \\
Better than even chance & 0.6 \\
Quite likely & 0.7 \\
Very likely & 0.8 \\
Nearly certain & 0.9 \\
Certain & 1 \\
\hline
\end{tabular}

Figure 6 Linguistic terms for probabilities

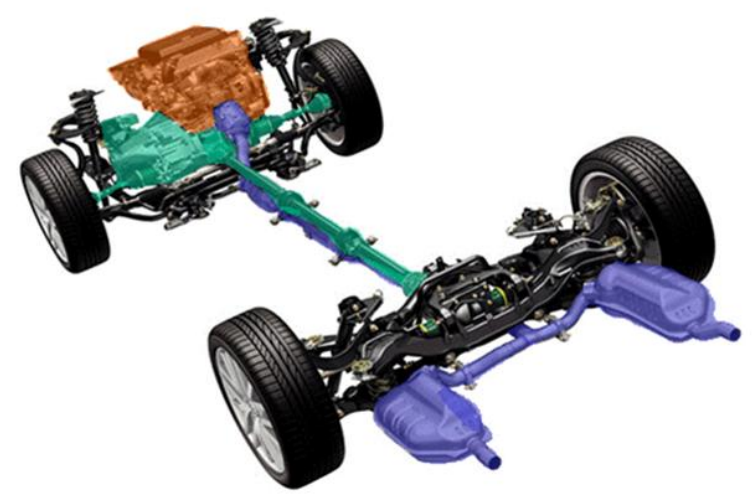

Figure 7Powertrain system of a modern automobile(Akehurst, 2007)

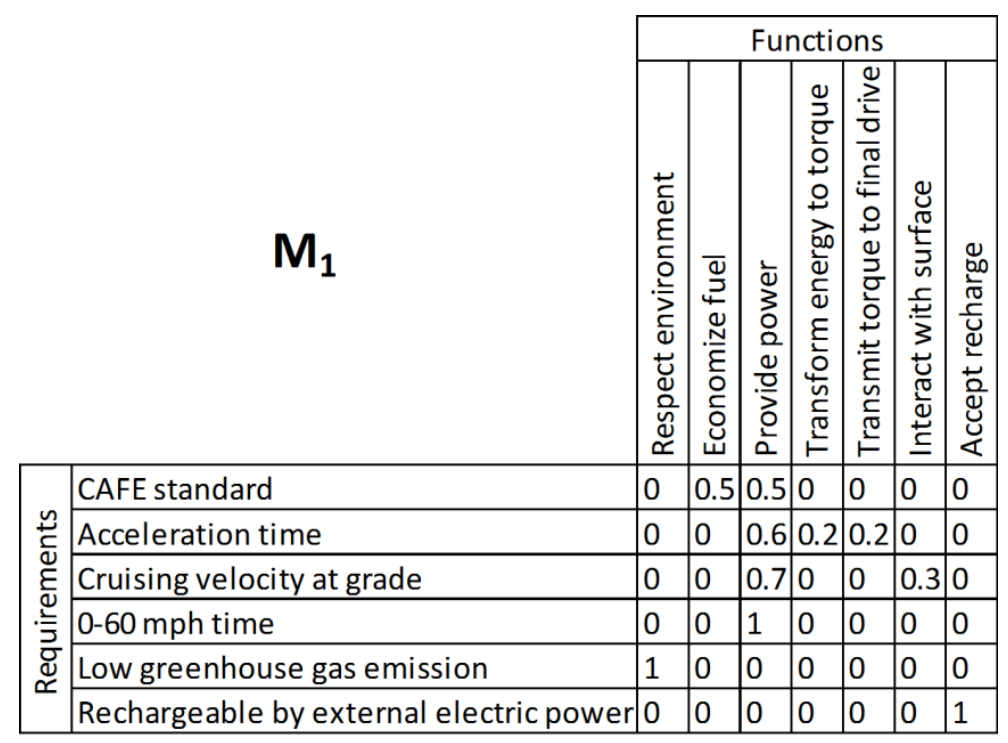

Figure 8 Requirement - function relations 


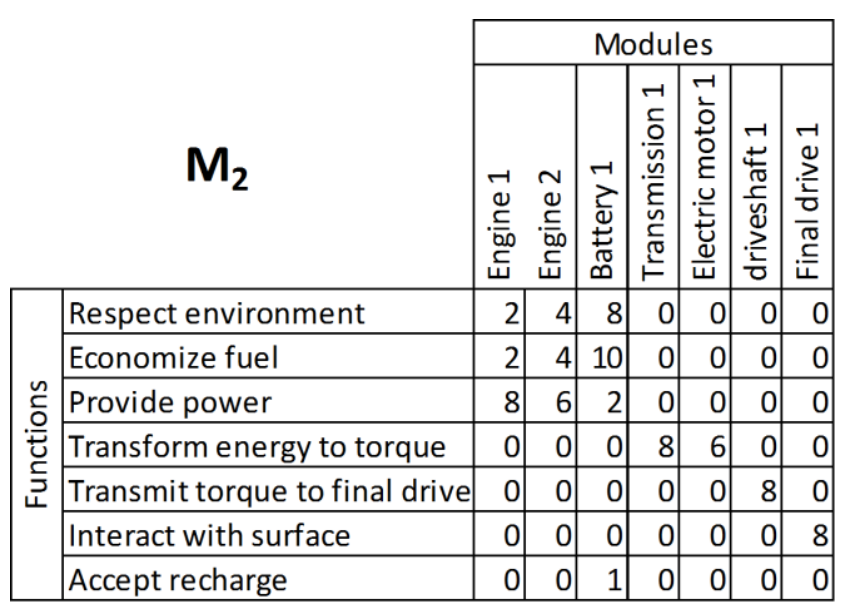

Figure 9 Function satisfaction level by modules

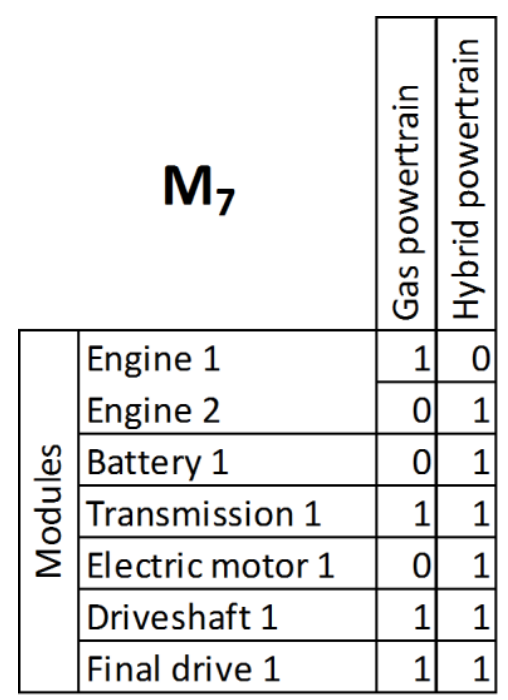

Figure 10Composition of existing powertrains

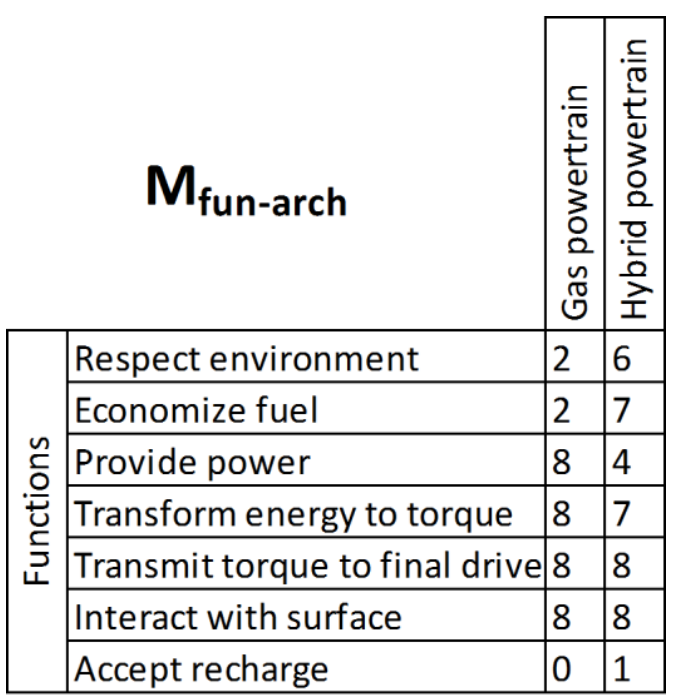

Figure 11 Function satisfaction level by existing products 


\begin{tabular}{|c|c|c|c|}
\hline \multicolumn{2}{|r|}{$\mathbf{M}_{\text {req-arch }}$} & 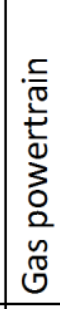 & 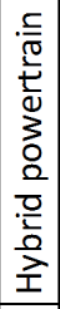 \\
\hline \multirow{6}{*}{ 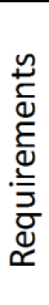 } & CAFE standard & 5 & 5.5 \\
\hline & Acceleration time & 8 & 5.4 \\
\hline & Cruising velocity at grade & 8 & 5.2 \\
\hline & $0-60 \mathrm{mph}$ time & 8 & 4 \\
\hline & Low greenhouse gas emission & 2 & 6 \\
\hline & Rechargeable by external electric power & 0 & 1 \\
\hline
\end{tabular}

Figure 12 Requirement satisfaction of existing products

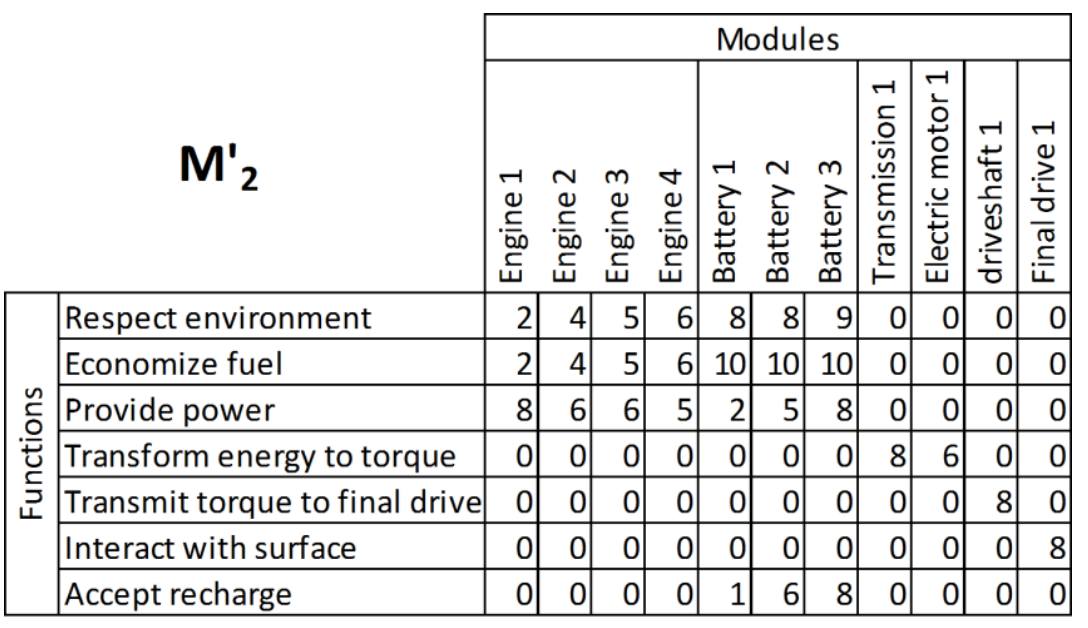

Figure 13Function - module relations with new modules

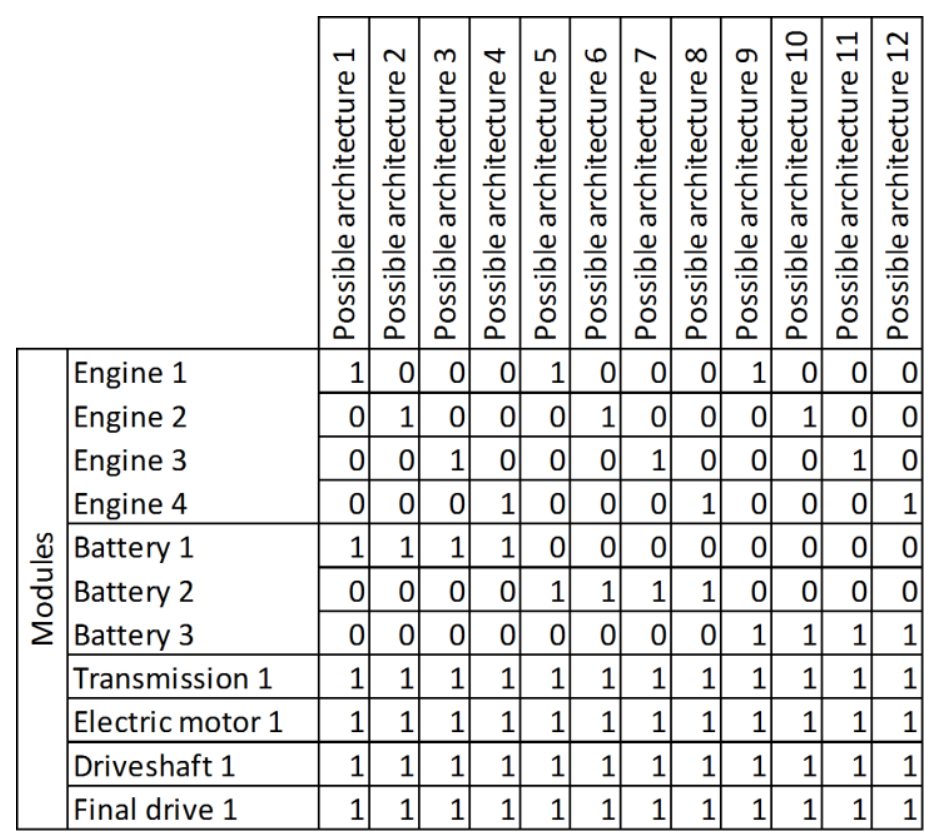

Figure 14 Generated possible architectures 
$M_{5}$

\begin{tabular}{|l|l|l|l|l|l|l|l|l|l|l|l|l|l|l|l|l|l|l|l|l|}
\hline 1.0 & 1.0 & 0.6 & 0.5 & 1.0 & 0.8 & 0.2 & 1.0 & 1.0 & 1.0 & 1.0 & Uncertainty & 1.0 & 0.5 & 0.8 & 1.0 & 0.3 & 1.0 & 1.0 & 1.0 & 1.0 \\
\hline
\end{tabular}

\begin{tabular}{|c|c|c|c|c|c|c|c|c|c|c|c|c|c|c|c|}
\hline 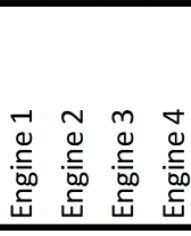 & 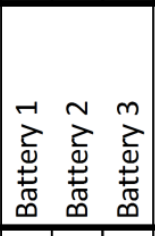 & 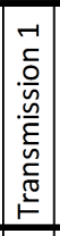 & 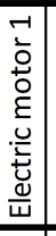 & 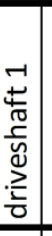 & 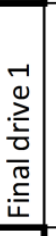 & & & 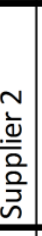 & 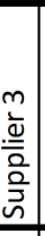 & 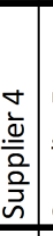 & 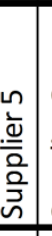 & 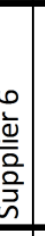 & 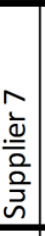 & & \\
\hline & \begin{tabular}{|l|l|l|}
0.2 & 0.0 & 0.3 \\
\end{tabular} & 1.0 & 0.3 & 1.0 & 1.0 & Engine 1 & 1 & 0 & 0 & 0 & 0 & 0 & 0 & & \\
\hline & \begin{tabular}{|l|l|l|}
1.0 & 0.5 & 0.2 \\
\end{tabular} & 1.0 & 1.0 & 1.0 & 1.0 & Engine 2 & 1 & 0 & 0 & 0 & 0 & 0 & 0 & 0 & 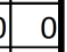 \\
\hline & \begin{tabular}{|l|l|l|}
0.2 & 0.8 & 0.6 \\
\end{tabular} & 0.8 & 0.6 & 0.8 & 0.8 & Engine 3 & 0 & 1 & 0 & 0 & 0 & 0 & 0 & 0 & \\
\hline & \begin{tabular}{|l|l|l|}
0.2 & 0.6 & 0.9 \\
\end{tabular} & 0.8 & 0.8 & 0.6 & 0.8 & Engine 4 & 0 & 0 & 1 & 0 & 0 & 0 & 0 & 0 & \\
\hline \begin{tabular}{|l|l|l|l|}
0.2 & 1.0 & 0.2 & 0.2 \\
\end{tabular} & & 1.0 & 1.0 & 1.0 & 1.0 & Battery 1 & 0 & 0 & 0 & 1 & 0 & 0 & 0 & 0 & \\
\hline \begin{tabular}{|l|l|l|l|}
0.0 & 0.5 & 0.8 & 0.6 \\
\end{tabular} & & 0.7 & 0.8 & 0.8 & 0.8 & Batter & $\underline{0}$ & 0 & 0 & 1 & 0 & 0 & 0 & 0 & \\
\hline \begin{tabular}{l|l|l|l|l|l|}
0.3 & 0.2 & 0.6 & 0.9 \\
\end{tabular} & & 0.9 & 0.8 & 0.9 & 0.8 & Battery 3 & 0 & 0 & 0 & 0 & 1 & 0 & 0 & 0 & \\
\hline \begin{tabular}{|l|l|l|l|l|}
1.0 & 1.0 & 0.8 & 0.8 \\
\end{tabular} & \begin{tabular}{|l|l|l|}
1.0 & 0.7 & 0.9 \\
\end{tabular} & & 1.0 & 1.0 & 1.0 & Transmission 1 & 0 & 0 & 0 & 0 & 0 & 1 & 0 & 0 & \\
\hline \begin{tabular}{l|l|l|l|}
0.3 & 1.0 & 0.6 & 0.8 \\
\end{tabular} & \begin{tabular}{|l|l|l|}
1.0 & 0.8 & 0.8 \\
\end{tabular} & 1.0 & & 1.0 & 1.0 & Electric motor 1 & 0 & 0 & 0 & 0 & 0 & 0 & 1 & 0 & \\
\hline \begin{tabular}{|l|l|l|l|}
1.0 & 1.0 & 0.8 & 0.6 \\
\end{tabular} & \begin{tabular}{|l|l|l|}
1.0 & 0.8 & 0.9 \\
\end{tabular} & 1.0 & & & 1.0 & Driveshaft 1 & $\underline{0}$ & 0 & 0 & 0 & 0 & 0 & 0 & 1 & \\
\hline \begin{tabular}{|l|l|l|l|}
1.0 & 1.0 & 0.8 & 0.8 \\
\end{tabular} & \begin{tabular}{|l|l|l|}
1.0 & 0.8 & 0.8 \\
\end{tabular} & 1.0 & 1.0 & 1.0 & & Final drive 1 & & 0 & 0 & 0 & 0 & & 0 & 0 & to \\
\hline
\end{tabular}

$\mathrm{M}_{4}$

Figure 15 Uncertainty information

\begin{tabular}{|c|r|r|r|r|r|r|r|r|r|r|r|r|}
\hline Architecture & 1 & 2 & 3 & 4 & 5 & 6 & 7 & 8 & 9 & 10 & 11 & 12 \\
\hline Uncertainty & 0.06 & 1.00 & 0.02 & 0.02 & 0.00 & 0.14 & 0.02 & 0.02 & 0.00 & 0.01 & 0.00 & 0.00 \\
\hline Satisfaction & 4.73 & 4.52 & 4.64 & 4.53 & 6.72 & 6.05 & 6.18 & 6.07 & 7.38 & 7.17 & 7.29 & 7.18 \\
\hline
\end{tabular}

Figure 16 Uncertainty and requirements satisfaction estimation for possible architectures

\begin{tabular}{|c|r|r|r|r|r|r|r|r|r|r|r|r|}
\hline Architecture & 1 & 2 & 3 & 4 & 5 & 6 & 7 & 8 & 9 & 10 & 11 & 12 \\
\hline Uncertainty & 0.06 & 1.00 & 0.02 & 0.02 & 0.00 & 0.14 & 0.02 & 0.02 & 0.00 & 0.01 & 0.00 & 0.00 \\
\hline Satisfaction & 4.73 & 4.52 & 4.64 & 4.53 & 6.72 & 6.05 & 6.18 & 6.07 & 7.38 & 7.17 & 7.29 & 7.18 \\
\hline
\end{tabular}

Figure 17Uncertainty and satisfaction filtering of possible architectures

\begin{tabular}{|c|c|c|}
\hline Differences & $\operatorname{CSM}$ & ASIT \\
\hline Objective & Ranking potential architectures & Identifying potential suppliers \\
\hline Results provide & $\begin{array}{l}\text { A ranking of architectures by using } \\
\text { satisfaction and compatibility scores }\end{array}$ & $\begin{array}{l}\text { A clustering of architectures and } \\
\text { suppliers by using satisfaction and } \\
\text { uncertainty threshold }\end{array}$ \\
\hline Estimation target & The satisfaction of functions & The satisfaction of requirements \\
\hline Definition of modules/concepts & $\begin{array}{l}\text { One function is satisfied by only one } \\
\text { concept and each concept can satisfy } \\
\text { only one function }\end{array}$ & $\begin{array}{l}\text { One function can be satisfied by one or } \\
\text { more modules, and one module can } \\
\text { satisfy several functions }\end{array}$ \\
\hline Consideration of uncertainty & No & Yes \\
\hline
\end{tabular}

Figure 18 Main differences between the CSM and the ASIT 


\begin{tabular}{|c|c|c|c|c|c|c|}
\hline \multicolumn{3}{|c|}{$\begin{array}{c}\text { CSM } \\
\text { (Ranking by score) } \\
\end{array}$} & \multicolumn{4}{|c|}{$\begin{array}{c}\text { ASIT } \\
\text { (Clustering: satisfaction } \geq 5 \text {, uncertainty } \geq 0.02 \text { ) }\end{array}$} \\
\hline Ranking & Architecture & Score & Architecture & Satisfaction & Uncertainty & Supplier \\
\hline 1 & 2 & 114.90 & 7 & 6.18 & 0.02 & $2,4,6,7,8,9$ \\
\hline 2 & 6 & 22.90 & 8 & 6.07 & 0.02 & $3,4,6,7,8,9$ \\
\hline 3 & 12 & 19.78 & 6 & 6.05 & 0.14 & $1,4,6,7,8,9$ \\
\hline 4 & 10 & 14.03 & & & & \\
\hline 5 & 11 & 13.10 & & & & \\
\hline 6 & 7 & 11.42 & & & & \\
\hline 7 & 8 & 8.62 & & & & \\
\hline 8 & 4 & 7.23 & & & & \\
\hline 9 & 3 & 7.17 & & & & \\
\hline 10 & 1 & 6.75 & & & & \\
\hline 11 & 9 & 6.20 & & & & \\
\hline 12 & 5 & 0 & & & & \\
\hline
\end{tabular}

Figure 19 Comparison of results between CSM and ASIT 
Yun YE is currently a $\mathrm{PhD}$ student in the Laboratory of Industrial Engineering at Ecole Centrale Paris. Her research focuses on the early supplier negotiation stage in complex system design. She accomplished her study of "Ingénieurgénéraliste" inEcole Centrale de Pékin and Ecole Centrale Paris. She has also a master degree of Industrial Engineering (from Ecole Centrale Paris), a master degree of Mechanical Engineering (From Beihang University), and a bachelor degree of Information and Computational Science (from Beihang University).

\section{Dr. Marija JANKOVIC}

Dr. Marija JANKOVIC is an Associate Professor in Industrial Engineering at Ecole Centrale Paris and a Deputy Director for Master Studies in Engineering Design and Management. She received her Bs.C in 2001 at Faculty of Organizational Sciences at University of Belgrade and M.S degree in Industrial Engineering from Ecole Centrale Paris in 2002. In majority of cases, her research projects are done in collaboration with industry or government; and with direct implementation and verification of research results. Therefore, Dr. Jankovic collaborates with some of the major French and international companies: Snecma, Thales, EADS, PSA Peugeot Citroen, Schlumberger, etc.

\section{Dr. Gül E. KREMER}

Dr. Kremer currently serves as a Program Director for the US National Science Foundation. Prior to joining NSF, she served as a Professor in the School of Engineering Design and Department of Industrial \& Manufacturing Engineering at The Pennsylvania State University. She also was a Fulbright Scholar to Ireland. Dr. Kremer has her Ph.D. in Engineering Management \& Systems Engineering from the University of MissouriRolla. and her M.B.A. in Production Management from Istanbul University. She received her Masters of Science and Bachelors of Science in Industrial Engineering from Yildiz Technical University in Istanbul, Turkey.

\section{Dr. Jean-Claude BOCQUET}

Dr.Jean-Claude BOCQUET is currently (and since 1987) professor and Director of the Laboratory of Industrial Engineering atEcole Centrale Paris. At the same time, he also serves asDirector of Educational Enterprise Sciences, Vice Chairman of the Board of Directors of ECP,Chairman of the Board of Directors CEESAR (European Center for Security Studies and Risk Analysis). He is expert at the Ministry of Research for research evaluation in Industrial Engineering for AERES and Expert for the ANR. He accomplished his Master in Mechanics and his Ph.D. in Mechanical CAD and Artificial Intelligence at ENS de Cachan, France. 